\title{
Anterior cervical plates: a historical perspective
}

\author{
Roham Moftakhar, M.D., and Gregory R. Trost, M.D. \\ Department of Neurosurgery, University of Wisconsin School of Medicine, Madison, Wisconsin
}

\begin{abstract}
The development of anterior cervical plates (ACPs) represents a rapidly changing aspect of spine surgery. This paper focuses on a historical overview of ACPs. The authors discuss the disadvantages of earlier generations of plates and demonstrate how current plates have been designed to overcome the presumed shortcomings of their predecessors.

This historical review begins with the earliest plates - unrestricted backout plates - and moves on to newer platesrestricted backout plates and their different subcategories.

Virtually all modern ACPs work equally well in cervical stabilization; however, there are differences in design that warrant future studies to understand the long-term performances of different plates.
\end{abstract}

KEY WORDS • anterior cervical plate • history of surgery $・$ spine stabilization

The first anterior cervical fusion was performed by Bailey and Badgley in the early 1950s. Cloward, ${ }^{6,7}$ Smith and Robinson, ${ }^{22}$ and others offered early contributions to the improvement of techniques of cervical fusion. These pioneers encountered high rates of pseudarthrosis and kyphosis in multilevel anterior procedures. This led to the development of an anterior internal cervical fixation device by Bohler in 1964, which was the foundation of the numerous plates available today. ${ }^{3}$

During the last 20 years ACPs have evolved. There have been improvements in fusion rates in patients undergoing multilevel anterior cervical fusion as well as in patients undergoing single-level fusion. Anterior cervical fusion has been shown to contribute to earlier patient mobilization, a decreased need for cervical collars postoperatively, an increased loading force applied to the graft, a decreased incidence of graft dislodgment, and an improved ability to fix spinal deformities. $1,2,4,5,8-10,12,14,17,21,23$

The proliferation of ACPs in the last two decades has warranted a need for a classification scheme, which was organized by Haid and colleagues in $2002 .{ }^{11}$ In this classification system, ACPs are first divided into two categories: unrestricted backout and restricted backout. Unrestricted backout plates, such as Orozco and Caspar plates,

Abbreviations used in this paper: $\mathrm{ACP}=$ anterior cervical plate; ASIF = Association for the Study of Internal Fixation; CSLP = Cervical Spine Locking Plate; DOC = Dynamic Osteosynthesis Cervical. are the earliest examples of ACPs and require the use of bicortical nonlocked bone screws. Restricted backout plates require the use of unicortical, locked bone screws and are further separated into the catagories of constrained and semiconstrained. Constrained plates have locked bone screws that do not allow motion at the plate-screw interface. Examples of constrained ACPs include the CSLP (Synthes), Orion (Medtronic Sofamor Danek), and Atlantis fixed (Medtronic Sofamor Danek) plates. On the other hand, semiconstrained plates have locked bone screws that allow motion of the construct. The semiconstrained plates are again classified as either rotational or translational. In the rotational category the locked bone screws are able to rotate at the plate-screw interface. Examples of rotational plates include Codman (Codman), Blackstone (Blackstone Medical), Peak (Depuy Acromed), Aline (Surgical Dynamics, Inc.), AcuFix (Spinal Concepts), Atlantis, and Zephir (Medtronic Sofamor Danek) plates. The other category of semiconstrained plates, translational plates, have locked bone screws that allow translation and rotation at the plate-screw interface. Examples of the translational plates include ABC (Aesculap), DOC (Depuy Acromed), and Premier (Medtronic Sofamor Danek) plates. Rotational and transitional plates are generally referred to as dynamic plates.

In this paper the evolution of ACPs will be reviewed. New generations of plates have been developed in an attempt to resolve the problems faced when using their predecessors. These problems will be discussed in this paper. 


\section{EARLY ANTERIOR CERVICAL PLATES}

\section{Unrestricted Backout Plates}

In 1970 Orozco and Llovet $^{16}$ were the first to report their use of a plate produced by the ASIF (Fig. 1). ${ }^{20}$ These authors used $\mathrm{H}$-shaped ASIF plates, which were the predecessors of the current plate made by Synthes Spine. In the early 1980s, Caspar popularized anterior cervical plating in collaboration with Aesculap, Inc. (Fig. 2). Orozco and Caspar plates were both unrestricted backout plates. In this construct, the screw angulation was determined by the patients' needs and the surgeon's preference..$^{5,20}$ These constructs did not have a fixed-moment arm and, furthermore, had limited fixation at the screw-plate interface. This led to greater exposure of the graft to compressive forces, allowing for a higher chance of fusion. The unrestricted backout plates had several disadvantages such as the demand for a bicortical screw purchase, which was technically demanding. Overpenetration could result in spinal cord injury, and underpenetration could result in construct failure and screw pullout. Furthermore, the cumbersome and difficult task of fluoroscopy was necessary to visualize the lower cervical regions. The Orozco and Caspar plates were nonrigid; that is, motion was allowed at the plate-screw interface.

\section{NEWER GENERATIONS OF ACPS}

\section{Restricted Backout Plates}

Constrained Systems. At the same time the Caspar plate was being developed, Raveh produced a titaniumcoated hollow-screw reconstruction plate at the University of Berne..$^{18}$ By inserting an expansion bolt into the lath, the screw was rigidly affixed to the plate, avoiding the need for a bicortical purchase. In Switzerland, Morscher modified the Orozco plate for use with unicortical, locking screws; this was reported in $1986 .{ }^{15}$ The system was introduced in US in 1991 by Synthes (Fig. 3). The Synthes CSLP did not require a bicortical purchase because a titanium expansion screw was used to affix the screw rigidly to the plate. ${ }^{10,19,20}$ The advantage of the unicortical screw purchase was that intraoperative fluoroscopy was not necessary and, thus, operative time was reduced. In addition,

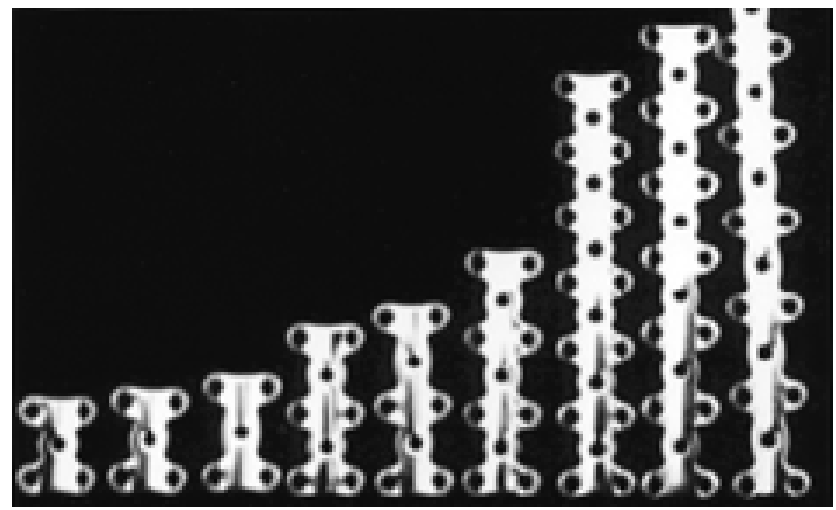

Fig. 1. Photograph showing $\mathrm{H}$-shaped ASIF plates, which were one of the earliest ACPs used.

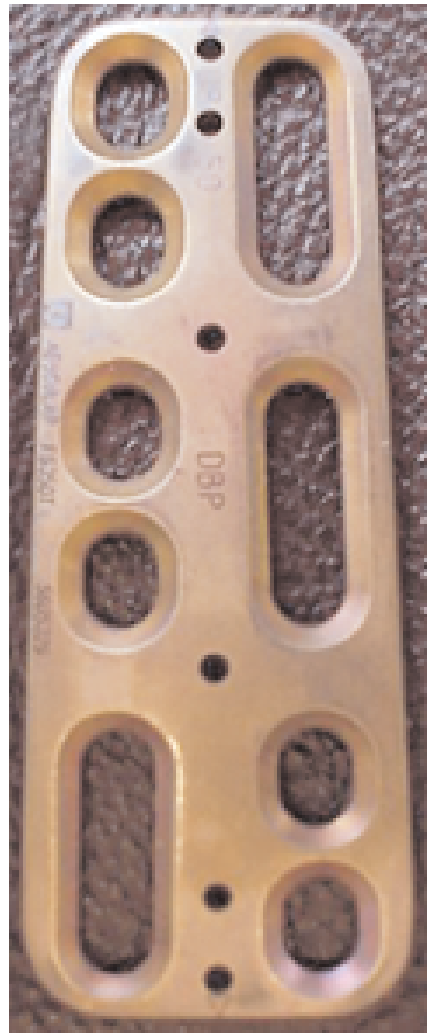

Fig. 2. Anterior view of the Caspar plate, which is an unrestricted backout plate.

the locking screw helped prevent screw backout. Another difference between the Caspar plate and the Synthes plate was that there was a fixed angle of entry for the screw and plate in the latter. The Synthes screw lengths were available in a limited range. Because the average diameter of an adult vertebral body ranges between 21 and $22 \mathrm{~mm}$, the risk of overpenetration past the posterior aspect of the vertebral body was rare. In the Synthes system the rostral screw was oriented $12^{\circ}$ cephalad, whereas the caudal screw was placed perpendicularly. One disadvantage of the original Synthes plate was that it was wide and diffi-

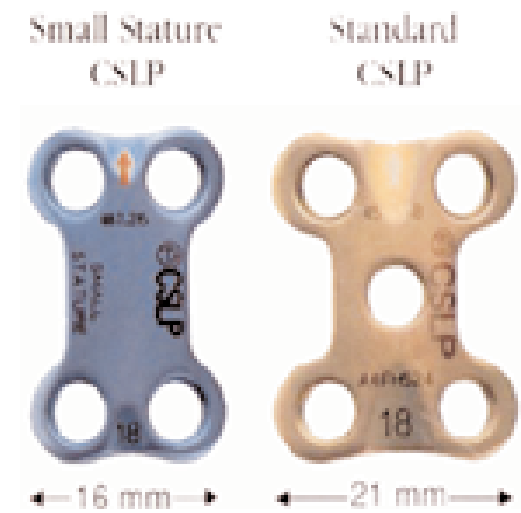

Fig. 3. Anterior view of the SCSLP, a restricted backout plate, available in two sizes. 
cult to contour. To resolve this problem in new Synthes plate the curvature radius was reduced from 25 to $15 \mathrm{~mm}$.

The Orion plating system, which was developed after the Synthes plate, offered a variable screw length (10-26 $\mathrm{mm}$ ) (Fig. 4). This allowed a unicortical or bicortical purchase to be achieved. One feature of the Orion plate was the prebent lordosis, which provided a better bone-plate interface. With the Orion plate, a drill guide that locked to the plate was used to ensure that the screws had a fixed angle. The angle of the screws used with this system was $15^{\circ}$ cephlad and caudal and $6^{\circ}$ medial. In theory this construct prevented screw pullout. In the Orion system a tapered screw, which had a core diameter of $2.4 \mathrm{~mm}$ and a thread diameter of $4 \mathrm{~mm}$, was used. The advantage of the tapered screw lay in the distribution of stress throughout the length of the screw; this decreased the risk of screw breakage. The Orion system had some disadvantages, however. For instance, some investigators found a high incidence of pseudarthrosis (12\%) in patients who underwent one-level anterior cervical discectomy and fusion. ${ }^{13}$ Furthermore, many surgeons believe that this plating system was too rigid and that, therefore, the plate absorbed the stress on the construct. ${ }^{11}$ This lack of stress may inhibit fusion.

Semiconstrained, Rotational Systems. The next generation of anterior cervical plating systems was the dynamic plates, which are also referred to as semiconstrained plates. This means that there were locked bone screws that allow motion of the construct. Dynamic plates have been divided into rotational plates, which allow rotation at the plate-screw interface, and translational plates, which allow axial translation and rotation. Examples of rotational semiconstrained plates are the Codman, Blackstone, Peak, Aline, Acufix, Deltaloc (Alphatec Manufacturing, Inc.), Zephir, and Atlantis (hybrid and variable) plates.

The Codman plate contained a cam lock to restrict backout (Fig. 5). This system was different from previous plates in that it allowed for variability in screw direction. The screws for this system were tapered to spread the stress along the length of the screw. This reduced the likelihood of screw breakage. The rotational screw-plate interface in the Codman system was designed in a way to increase the load on the graft, therefore increasing the rate of graft fusion. Although good results have been achieved

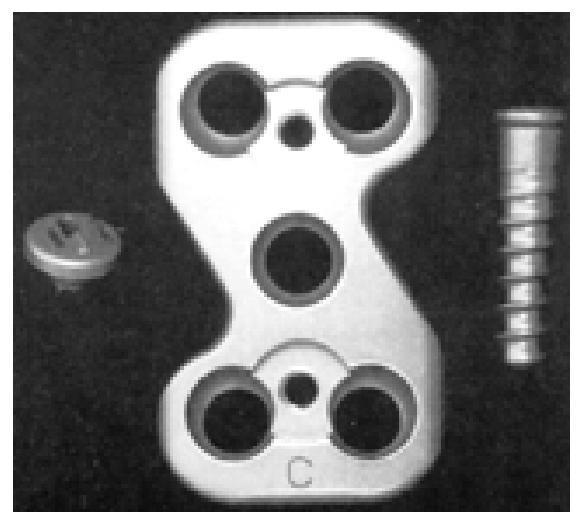

Fig. 4. Anterior view of the Orion plate and screw; this ACP is a constrained, restricted backout plate.

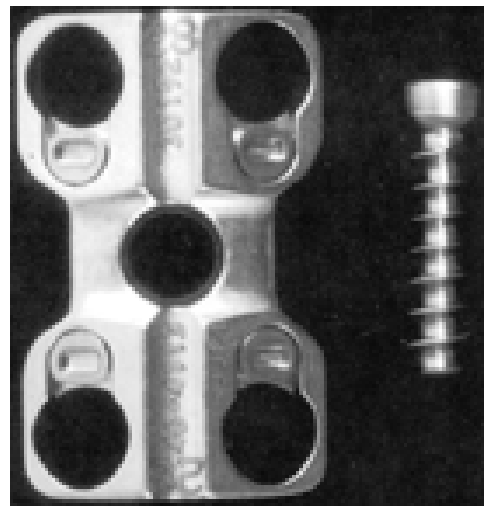

Fig. 5. Anterior view of the Codman plate and screw; this ACP is a semiconstrained, rotational system with a restricted backout feature.

using the Codman plate for short and intermediate segment fixation, treatment failure has occurred in patients with multilevel corpectomies or unstable spines without posterior fixation. ${ }^{11}$ Codman's newest ACP is SLIM-LOC. The company claims that this is the smallest ACP available on the market. The profile of the plate is $2.1 \mathrm{~mm}$. This system comes with a choice of screws that range from self-tapping to self-drilling screws.

\section{Restricted Backout Plates}

Semiconstrained, Translational Devices. Translational plates were designed to provide translation and rotation at the screw-plate interface. Movement at the screw-plate interface was planned to avoid stress shielding so that, theoretically, fusion rates would increase and time to fusion would diminish. This concept follows the Wolff law, which suggests that loading alters bone integrity and bone healing, ${ }^{2}$ that is, bone heals more optimally when exposed to a compressive load. Examples of translational devices include ABC, DOC, and Premier plates. Dupuy Acromed developed the first translational system, which was referred to as the DOC rod (Fig. 6). This plate was designed so that the cephalad screws would be able to slide along a rail, whereas the caudal screws would remain rigid. Using the DOC plate the extent of axial deformation could be controlled by a cross-fixator that allows the implant to control the amount of settling (controlled dynamism). The newer version of this plate, which is now referred to as the DOC plate, is a rigid implant in which a two-piece locking expansion screw system is used. This plate allows for the intraoperative visibility of the bone graft through its specially designed "graft site window." The preset screw trajectories are designed to create a $15^{\circ}$ superior and inferior screw path along with a $5^{\circ}$ medial trajectory.

The ABC plating system designed by Aesculap is both a translational and rotational system (Fig. 7). The Premier plate, manufactured by Medtronic Sofamor Danek, allows for a translational motion of the screw that is similar to that seen when using the DOC plate. Screws first translate in a slot and may then rotate after maximum translation.

\section{Multiconstruct Systems}

The Atlantis ACP system is one of the newest plate sys- 


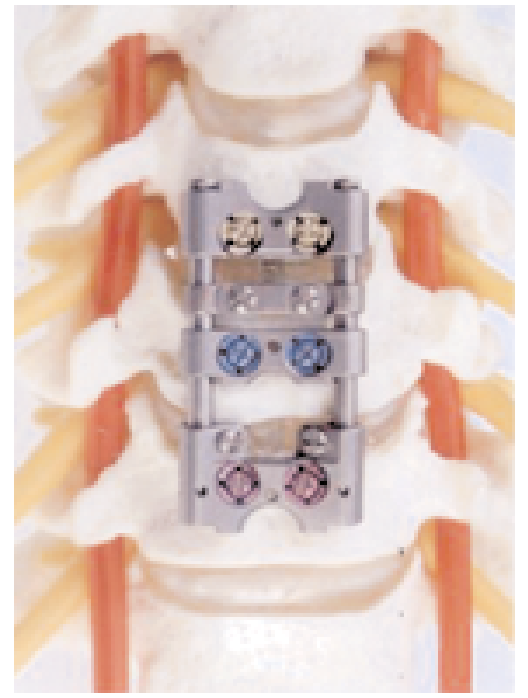

Fig. 6. Anterior view of the DOC rod. At the top is the plate's cross-fixator, which controls the extent of settling.

tems and can be used with either a variable-angle screw or a fixed-angle screw. In other words, a construct can be created that is rigid, rotational, or a "hybrid" (combining technologies).

In the fixed Atlantis construct two fixed-angle screws that allow no rotation or translation are used. The screws are angled at $12^{\circ}$ cephlad and caudal and $6^{\circ}$ medially. The variable Atlantis system is similar to the Codman plate system in that it includes two sets of variable angle screws and allows for rotational motion for both the superior and inferior sets of screws.

The hybrid Atlantis system includes fixed-angle and variable-angle screws. The advantage of the hybrid system is that compressive forces can promoted bone graft

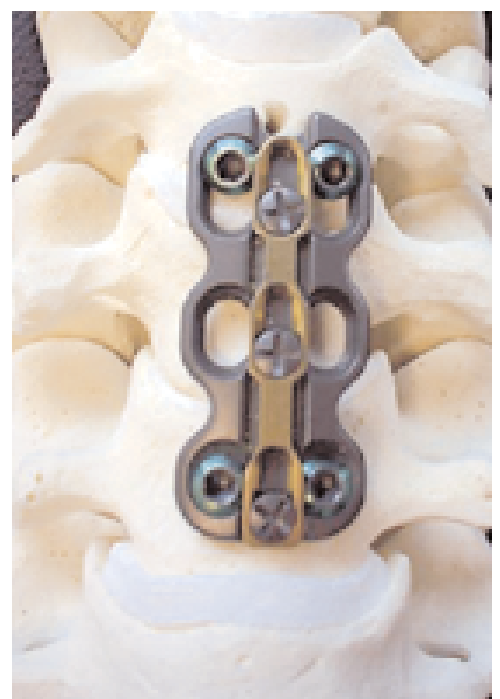

Fig. 7. Anterior view of the ABC plate and screw; this ACP is a semiconstrained, translational device with a restricted backout feature. and fusion. Haid and colleagues ${ }^{11}$ have found this Atlantis construct to be useful in performing cervical corpectomies and discectomies. Furthermore, this group has found that the fusion rates and clinical outcome, achieved using the Atlantis system match or exceed the results obtained using other plates.

\section{CONCLUSIONS}

Over the past 20 years, although the basic design of ACPs has stayed the same, several important features have been added to the newer generation of plates. Although all the current cervical plates provide appropriate fusion success, it is important to know which plate fits the patient's needs. Newer types of plates, such as semiconstrained rotational and translational systems and multiconstruct systems, still need to be studied in detail. The development of newer ACPs will depend on what we have learned from the shortcomings of the plates available today.

\section{Disclaimer}

The authors have no financial interest in any of the manufacturers of ACPs mentioned in this paper.

\section{References}

1. Barnes B, Haid RW, Rodts GE, et al: Early results using the Atlantis anterior cervical plate system. Neurosurg Focus 12 (1): Article 13, 2002

2. Benzel EC: Biomechanics of Spine Stabilization. Rolling Meadows, IL: AANS, 2001, pp 437-440

3. Bohler J, Gaudernak T: Anterior plate stabilization for fracture-dislocations of the lower cervical spine. J Trauma 20: 203-205, 1980

4. Bose B: Anterior cervical fusion using Caspar plating: analysis of results and review of the literature. Surg Neurol 49:25-31, 1998

5. Caspar W, Barbier DD, Klara PM: Anterior cervical fusion and Caspar plate stabilization for cervical trauma. Neurosurgery 25:491-502, 1989

6. Cloward RB: The anterior approach for removal of ruptured cervical disks. J Neurosurg 15:602-617, 1958

7. Cloward RB: Treatment of acute fractures and fracture-dislocations of the cervical spine by vertebral-body fusion. A report of eleven cases. J Neurosurg 18:201-209, 1961

8. Epstein NE: The management of one-level anterior cervical corpectomy with fusion using Atlantis hybrid plates: preliminary experience. J Spinal Disord 13:324-328, 2000

9. Griffith SL, Zogbi SW, Guyer RD, et al: Biomechanical comparison of anterior instrumentation for the cervical spine. J Spinal Disord 8:429-438, 1995

10. Grubb MR, Currier BL, Shih JS, et al: Biomechanical evaluation of anterior cervical spine stabilization. Spine 23:886-892, 1998

11. Haid RW, Foley KT, Rodts GE, et al: The Cervical Spine Study Group anterior cervical plate nomenclature. Neurosurg Focus 12 (1):Article 15, 2002

12. Katsuura A, Hukuda S, Imanaka T, et al: Anterior cervical plate used in degenerative disease can maintain cervical lordosis. J Spinal Disord 9:470-476, 1996

13. Lowery GL, McDonough RF: The significance of hardware failure in anterior cervical plate fixation. Patients with 2- to 7year follow-up. Spine 23:181-187, 1998

14. Mayr MT, Subach BR, Comey CH, et al: Cervical spinal stenosis: outcome after anterior corpectomy, allograft reconstruction, and instrumentation. J Neurosurg (Spine 1) 96:10-16, 2002 
15. Morscher E, Sutter F, Jenny H, et al: Die vordere Verplattung der Halswirbelsaule mit dem Hohlschrauben-plattensystem aus Titanium. Chirurg 57:702-707, 1986

16. Orozco DR, Llovet TR: Osteosintesis en las lesions traumaticas y degeneratives de la columna vertebral. Revista Traumatol Cirurg Rehabil 1:45-52, 1971

17. Paramore CG, Dickman CA, Sonntag VK: Radiographic and clinical follow-up review of Caspar plates in 49 patients. J Neurosurg 84:957-961, 1996

18. Raveh J, Stich H, Sutter F, et al: Use of titanium-coated hollow screw and reconstruction plate system in bridging of lower jaw defects. J Oral Maxillofac Surg 42:281-294, 1984

19. Rechtine GR, Cahill DW, Gruerenberg M, et al: The Synthes cervical spine locking plate and screw system in anterior cervical fusion. Tech Orthop 9:86-91, 1994

20. Rengachary SS, Sanan A: Anterior stabilization of the cervical spine using locking plate and screw systems, in Wilkins RH, Rengachary SS (eds): Neurosurgery, ed 2. New York: McGraw-Hill, 1996, Vol II, pp 2983-2986
21. Schultz KD Jr, McLaughlin MR, Haid RW Jr, et al: Singlestage anterior-posterior decompression and stabilization for complex cervical spine disorders. J Neurosurg (Spine 2) 93: 214-221, 2000

22. Smith GW, Robinson RA: The treatment of certain cervicalspine disorders by anterior removal of the intervertebral disc and interbody fusion. J Bone Joint Surg Am 40-A:607-624, 1958

23. Wang JC, McDonough PW, Endow K, et al: The effect of cervical plating on single-level anterior cervical discectomy and fusion. J Spinal Disord 12:467-471, 1999

Manuscript received November 17, 2003.

Accepted in final form December 11, 2003.

Address reprint requests to: Gregory R. Trost, M.D., Department of Neurological Surgery, University of Wisconsin Hospital and Clinics, K4/822 Clinical Science Center, 600 Highland Avenue, Madison, Wisconsin 53792. email: trost@ neurosurg.wisc.edu. 